\title{
Simultaneous Magnetic Measurements and Their Comparison at the Sea Floor Using a Fluxgate Vector Magnetometer and a Proton Scalar Magnetometer
}

\author{
Kin-ichiro Kolzumi ${ }^{1}$, Jiro Segawa ${ }^{1}$, Hiroaki TOH $^{1}$, Jose L. Oubina CARretero ${ }^{1}$, and \\ Yaichi TANAKA ${ }^{2}$ \\ 'Ocean Research Institute, University of Tokyo, 15-1, 1-chome, Minamidai, \\ Nakano-ku, Tokyo 164, Japan \\ ${ }^{2}$ Kokusai Electronics Incorporated, 34-10, 5-chome, Minamidai, Nakano-ku, Tokyo 164, Japan
}

(Received October 1, 1988; Revised January 16, 1989)

\begin{abstract}
In order to examine the instability of the three-component ocean bottom magnetometer, we have developed an ocean bottom proton magnetometer and made comparison measurements at the sea floor using both fluxgate and proton magnetometers. The comparison was made in 1987 at $30^{\circ} 57^{\prime} .1 \mathrm{~N}, 140^{\circ} 39^{\prime} .1 \mathrm{E}$ near the Izu-Bonin Arc. We were able to obtain data from this measurement for as long as 77 days with two-minute sampling intervals. Although we tried to install the two meters as close together as possible, it was later found that the separation between the two meters was $487 \mathrm{~m}$. The difference in the absolute value between the fluxgate and the proton magnetometer was approximately $100 \mathrm{nT}$, which may have been caused by the difference of the sites of installation. The result of comparison as to long-term changes shows that the three-component vector magnetometer used for the comparison was unstable for a few days after installation and then stabilized, and that the drift rate during the stable period was not larger than $0.27 \mathrm{nT} /$ day.
\end{abstract}

\section{Introduction}

Since magnetic measurement at the sea floor was started in 1980, we have been accumulating data in various seas (SEGAWA et al., 1982, 1983). Our magnetometer for sea floor use to measure components of the geomagnetic field variation is of the fluxgate type, which is likely to be subject to drift with time. It is not easy to separate the drift component from the measurement, because natural geomagnetic change contains components with similar periods as those of the long-term instrumental drift. From 1986 we have been developing a sea floor proton magnetometer in order to obtain an absolute scalar reference which enables us to judge if there is any drift in the fluxgate magnetometer.

We have made measurements at sea using the proton magnetometer three times. The first experiment, carried out in May 1986, proved to be a failure, and the second one from July to September in the same year gave us only two-day data, those in the rest period having been missed. The third experiment was conducted 
from July to September 1987, when both the proton magnetometer and the fluxgate magnetometer were installed at about the same place. From the last experiment we could obtain both three-component magnetic data and total magnetic intensity data for a period longer than 70 days.

This paper describes the proton magnetometer developed for sea floor use and discusses the results of comparison between the measurements by the fluxgate vector magnetometer and the proton scalar magnetometer.

\section{Ocean Bottom Proton Magnetometer (OBP)}

The proton magnetometer for sea floor measurement was named the Ocean Bottom Proton Magnetometer (OBP). Figure 1 shows its schematic design; the sensor coil is of the toroidal type with a diameter of $122 \mathrm{~mm} \varnothing$, a thickness of $97 \mathrm{~mm}$ and an inductance of $18 \mathrm{mH}$, and is totally dipped in kerosene. This sensor is housed in a pressure-tight glass sphere 10 inches in diameter and supported by an aluminum frame. The output signals from the proton sensor are counted and converted to nT units with a resolution of $0.5 \mathrm{nT}$. The data are recorded on a ROM card. The most important factor in using the OBP is that the proton sensor has to be set at a place distant from the other electronics. The magnetic effect from the electronic units, particularly from the batteries, is very large. The sensor of the OBP was moved about $1.5 \mathrm{~m}$ apart from the vessel which housed the electronics units. After doing this, the magnetic bias caused by the electronic components was reduced to less than $5 \mathrm{nT}$.

The OBP is installed at the sea floor by the "free-fall" method from the sea surface and retrieved by releasing a weight by use of an acoustic release. Figure 2 shows a picture of the OBP prior to installation. The DC current to excite the sensor coil was $1.7 \mathrm{Amp}$ and the current duration was $1.38 \mathrm{sec}$ for the 1986 experiment. In the 1987 experiment, the current was reduced to $1.0 \mathrm{Amp}$ with the same excitation duration. The interval of measurement was $5 \mathrm{~min}$ in 1986 and $2 \mathrm{~min}$ in 1987. The electric power was supplied from lithium batteries which were turned on during the $4.7 \mathrm{sec}$ measurement period and turned off during the rest period to save power. The average power consumption was about $250 \mathrm{~mA}$ during measurement and about 1 $\mathrm{mA}$ during the idling time.

Since we use the proton magnetometer as reference data, we must first estimate the possible error in the total intensity obtained from the proton magnetometer. Although the frequency of proton precession is not affected by a change of environment and/or electronics, its frequency readings do change with changes in its standard clock. Figure 3 shows the result of a test to examine the gate interval change of the frequency counter due to the temperature effect of the OBP crystal clock. As the frequency of the output proton precession is multiplied by 64 , the relationship between the output frequency $f$ and the intensity of magnetic field $F$ in $\mathrm{nT}$ is expressed by letting the Larmor constant be $\gamma_{\mathrm{p}}=2.6751927 \times 10^{4} \mathrm{~s}^{-1} \mathrm{G}^{-1}$, as 


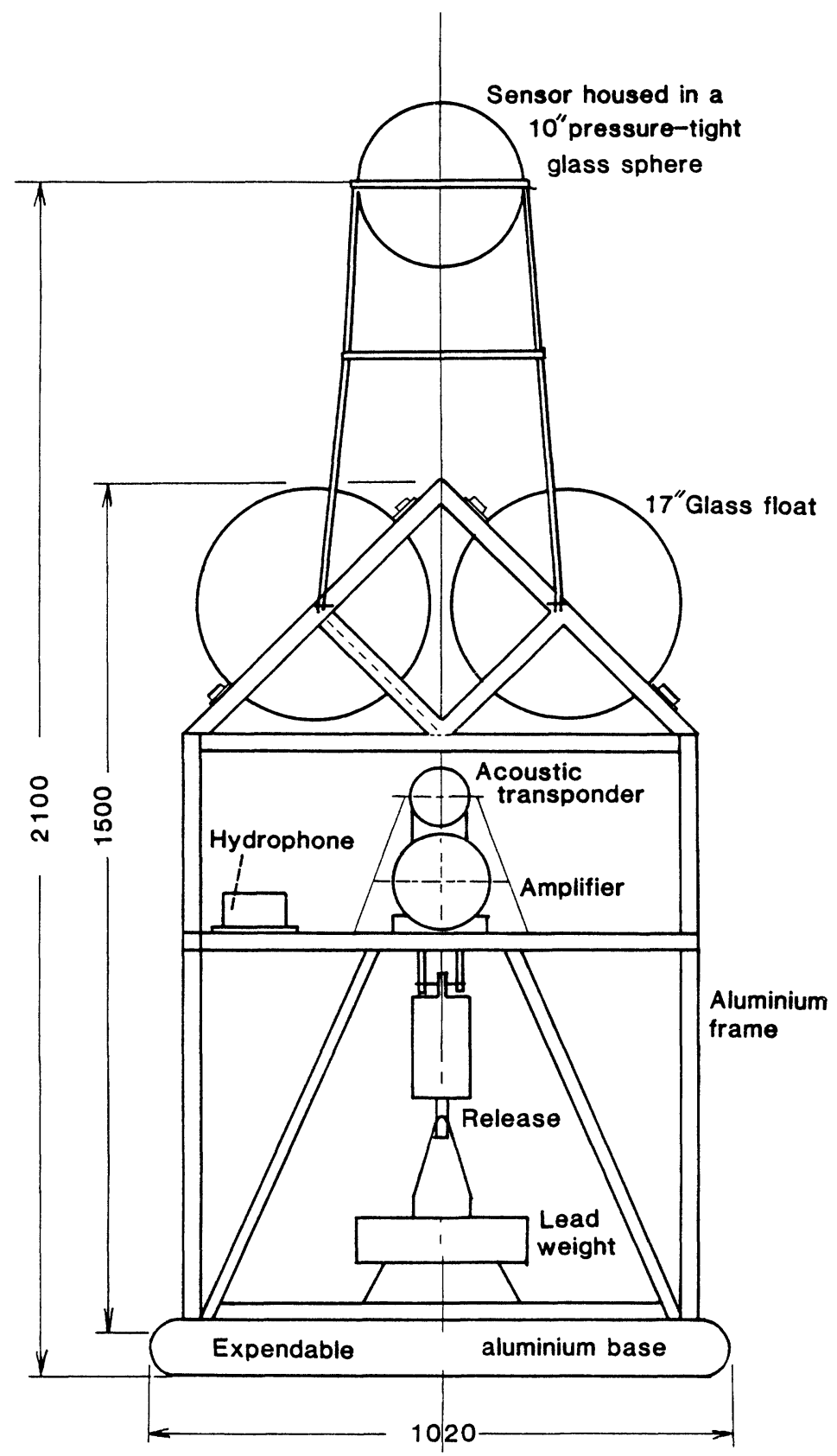

Fig. 1. A schematic design of the ocean bottom proton magnetometer. The sensor coil housed in a 10" glass sphere is installed at the top of the aluminum frame, $1.5 \mathrm{~m}$ above the aluminum cylinder which contains the electronic units. 


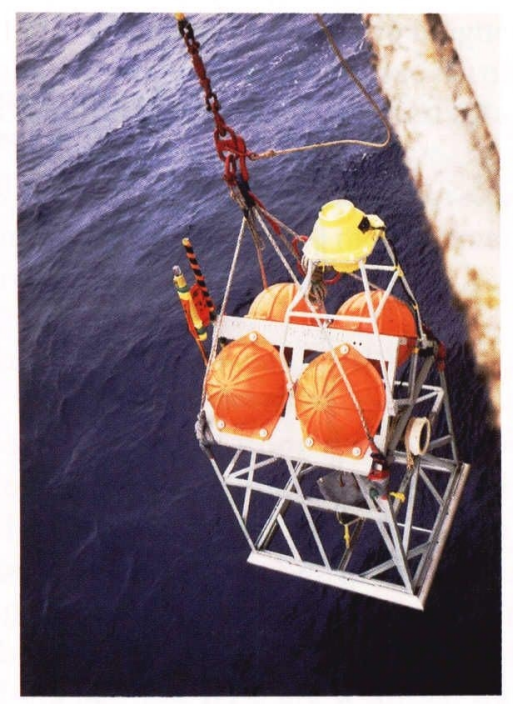

Fig. 2. Outer view of the ocean bottom proton magnetometer being installed.

$$
\begin{aligned}
F & =\left(\omega \times 10^{5}\right) /\left(\gamma_{\mathrm{p}} \times 64\right) \\
& =0.366990 \times f,
\end{aligned}
$$

where $\omega$ is the angular frequency of proton precession and $\mathrm{G}$ means Gauss units. So, the gate interval of measuring frequency is taken at $366.990 \mathrm{msec}$ in order to obtain a resolution better than $0.5 \mathrm{nT}$. The change in the gate interval due to ambient temperature was examined over a temperature range from $-4^{\circ} \mathrm{C}$ to $+40^{\circ} \mathrm{C}$ when the OBP electronics were totally installed inside a temperature-controlled housing. In Fig. 3 the change of gate interval is plotted by open circles against the ambient temperature. This figure shows that the gate interval change caused by the change in ambient temperature is not larger than $0.5 \mu \mathrm{sec} /{ }^{\circ} \mathrm{C}$. In sea floor environments, with the temperature $1^{\circ} \mathrm{C}$ to $2^{\circ} \mathrm{C}$, this rate decreases to about $0.1 \mu \mathrm{sec} /{ }^{\circ} \mathrm{C}$. The drift of the gate interval with time is, on the other hand, known to be more or less 0.15 $\mu \mathrm{sec} /$ month, which is considered negligibly small in the present case. Considering that the water temperature at the deep sea floor is nearly $1^{\circ} \mathrm{C}$, and that it changes by $0.1^{\circ} \mathrm{C}$ or less over a period of a few months, the total change of the gate interval during a few-month period will be less than $0.5 \mu \mathrm{sec}$. This implies that for measurements where the total magnetic intensity is $45,000 \mathrm{nT}$, the error $\Delta F$ of measurement due to the instability of the gate interval is

$$
\frac{\Delta F}{45000}<\frac{0.0000005}{0.366990}
$$




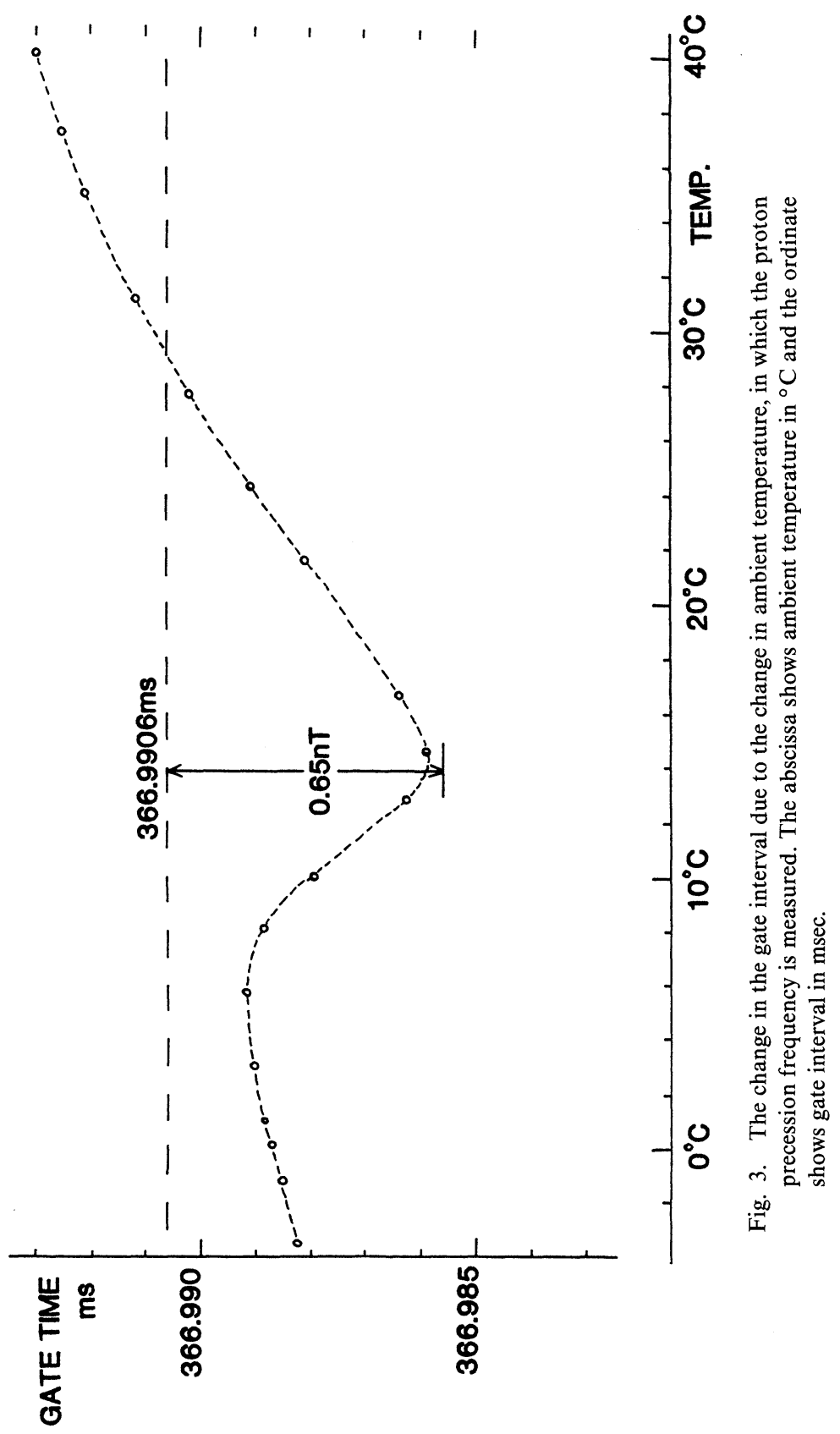


Equation (2) implies that the possible error in the reference total intensity is less than $0.06 \mathrm{nT}$.

\section{Ocean Bottom Fluxgate Magnetometer (OBM-C3)}

Figure 4 shows the fluxgate magnetometer for sea floor use which was used for comparison measurement. This model, named the OBM-C3, was designed in 1986 for the purpose of getting better accuracy in the absolute values. The difference in this magnetometer from previously used ones (SEGAWA et al., 1982, 1983, 1986) is that the three-component sensor is installed about $1.5 \mathrm{~m}$ apart from the other electronic units. The magnetic sensor, made of circular permalloy cores, is mounted on a non-magnetic free gimbal which is completely soaked in silicon damping oil. The dynamic angle of the gimbal is $20^{\circ}$. The amplifier and recorder units are housed in a pressure-tight aluminum vessel, which is installed at the bottom of the aluminum frame. The acoustic transponder and the release mechanism are also installed at the bottom plane of the frame.

The magnetic effects of these units on the sensor is about $5 \mathrm{nT}$; this means that if there were a slight change of magnetization in the electronic units, its effect on the sensor might be very small, presumably on the order of $0.1 \mathrm{nT}$. The accuracy of sensitivity calibration is $10^{-5}$, corresponding to a $0.5 \mathrm{nT}$ error in a magnetic field of $50,000 \mathrm{nT}$. This calibration was carried out using a Helmholtz coil at the Geomagnetic Observatory at Kakioka.

The scale factors of the OBM-C3 are shown in Table 1. There are two kinds of scale factors for each component: One is the factor for the coarse values, which step up by $200 \mathrm{nT}$ units; the other is the factor for the fine values, which are applied to the range within $\pm 200 \mathrm{nT}$. Figure 5 shows the results of a comparison between the OBM-C3 and KASMMER (Kakioka Automatic Standard Magnetometer) which was carried out for 4 days at the Geomagnetic Observatory at Kakioka.

\section{Comparison of Measurements}

Figure 6 shows the installation sites for the comparison measurements. The installation locations are given in Table 2. In the 1986 experiment, the OBP worked only for the first 42 hours, and no data were recorded after that for an unknown reason. The 1987 experiment was successful, and 77-day data were obtained from both the OBP and OBM-C3. The 1986 OBP data are shown in Fig. 7, as 42-hour data with samplings every $5 \mathrm{~min}$. The approximate total value of the magnetic field was found to be 44,150 nT at this site. Figure 8 shows an example of measurement with samplings every 2 min for the 1987 experiment. The illustrated data are oneday-length data on July 6 . The approximate OBP value at this site was 43,400 nT. Figure 8 also shows, for comparison, the total magnetic intensity data observed at the Hachijo-shima Hydrographic Observatory, the third Regional Maritime Safety Headquarters, which is located about $240 \mathrm{~km}$ north of the sea floor sites.

What was commonly observed with the OBP data at the sea floor is that 


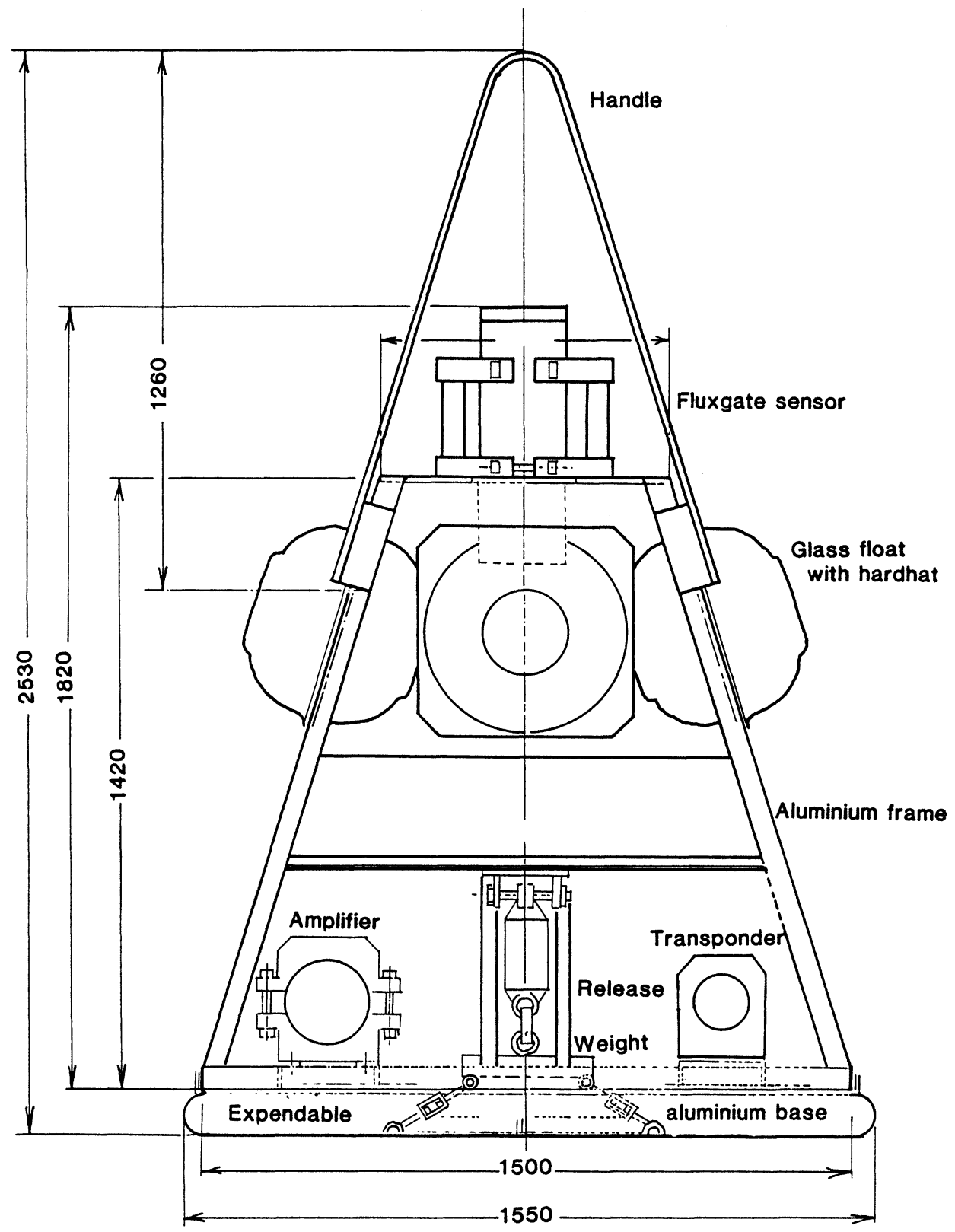

Fig. 4. Design of the fluxgate vector magnetometer OBM-C3. 
Table 1. Scale factors of OBM-C3. Fine: Scale factor for the fine range, i.e., the range from $-199.9 \mathrm{nT}$ to $+199.9 \mathrm{nT}$. Unit nT/unity. Coarse: Scale factor for the coarse range with a step of $200 \mathrm{nT}$. Unit $\mathrm{nT} /$ unity.

\begin{tabular}{cllc}
\hline & \multicolumn{1}{c}{$X$-axis } & \multicolumn{1}{c}{$Y$-axis } & \multicolumn{1}{c}{$Z$-axis } \\
\hline Fine & 0.992048 & 0.997561 & 1.00673 \\
Coarse & 1.0098 & 1.00249 & 1.01071 \\
\hline
\end{tabular}

UNIT: nT/unity.

unexplainable fluctuations of the data with an amplitude of $3 \mathrm{nT}$ were seen. This fluctuation seems comparatively small in the case of the 1986 experiment, particularly during the first 12 hours. In this experiment the current to excite the coil was 1.7 Amp; a test on land showed that $1 \mathrm{Amp}$ exciting current was large enough to get stable readings. Although it is not clearly understood, the proton sensor might not have been sufficiently energized due to deterioration of the lithium battery in the low temperature environments at the sea floor. In Fig. 8, a smoothed profile of the OBP data from the 1987 experiment is also shown. Smoothing was done by taking running averages of 5 successive readings, corresponding to a 10-minute average. The smoothed profile still shows fluctuations with an amplitude of $1 \mathrm{nT}$ and a period of a few tens of minutes. If these fluctuations are compared with the data from Hachijo-shima island, some of them correspond to the natural change of magnetic field and some do not.

As the primary objective of using a proton magnetometer together with a fluxgate magnetometer is to check the drift characteristics of the latter, the longterm change of total magnetic intensity was compared, as seen in Fig. 9. The profiles show one-day data, in which the upper profile is from the OBP and the lower profile is the total magnetic field synthesized from the three-component data of the fluxgate magnetometer, OBM-C3. As the total fields obtained in this way do not agree, 100 $\mathrm{nT}$ is subtracted from the actual values of the OBM-C3 in Fig. 9 for easy comparison. These profiles are drawn by taking 31 running averages, or 60 -minute running averages of the raw data. The difference in total values between the two measurements may be due primarily to the difference of the sites where the two magnetometers were installed. Since the OBM-C3 was strictly calibrated at the Geomagnetic Observatory at Kakioka and its instrumental offset is less than $5 \mathrm{nT}$, as mentioned in Section 3, there is no possibility of an error as large as $100 \mathrm{nT}$ being caused by the OBM-C3 itself. The distance between the OBP site and the OBM-C3 site was approximately $487 \mathrm{~m}$. Considering the sites are located on the Izu-Bonin volcanic arc, it is not unreasonable that a slight departure of position should cause a difference in magnetic field as large as $100 \mathrm{nT}$. In Fig. 10 the differences are plotted between readings of the OBM-C3 and OBP, i.e., (OBM-C3 minus $95 \mathrm{nT}$ ) minus OBP, using smoothed data as in the case of Fig. 9. Plottings were made every four hours over a period of 77 days. 


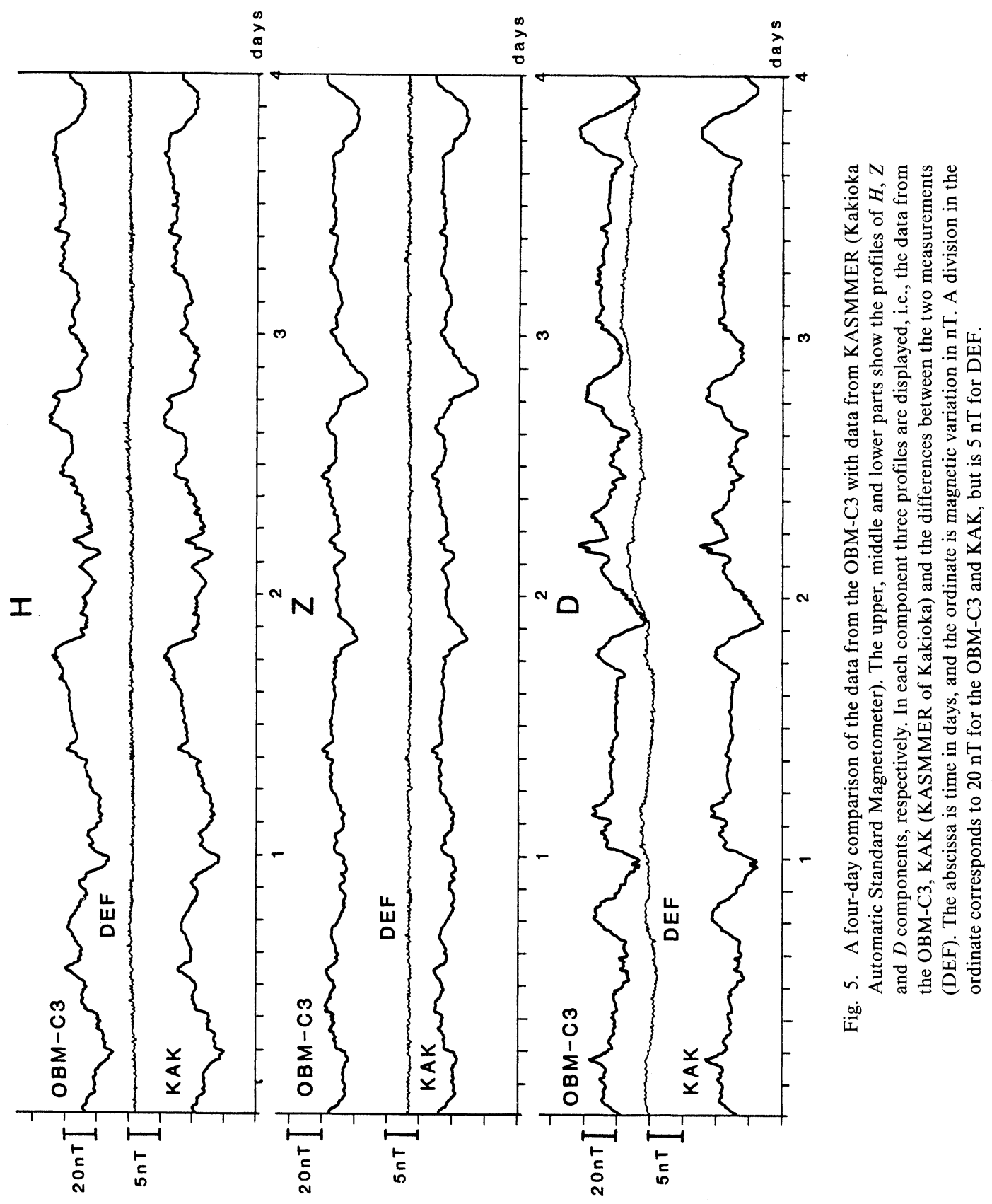




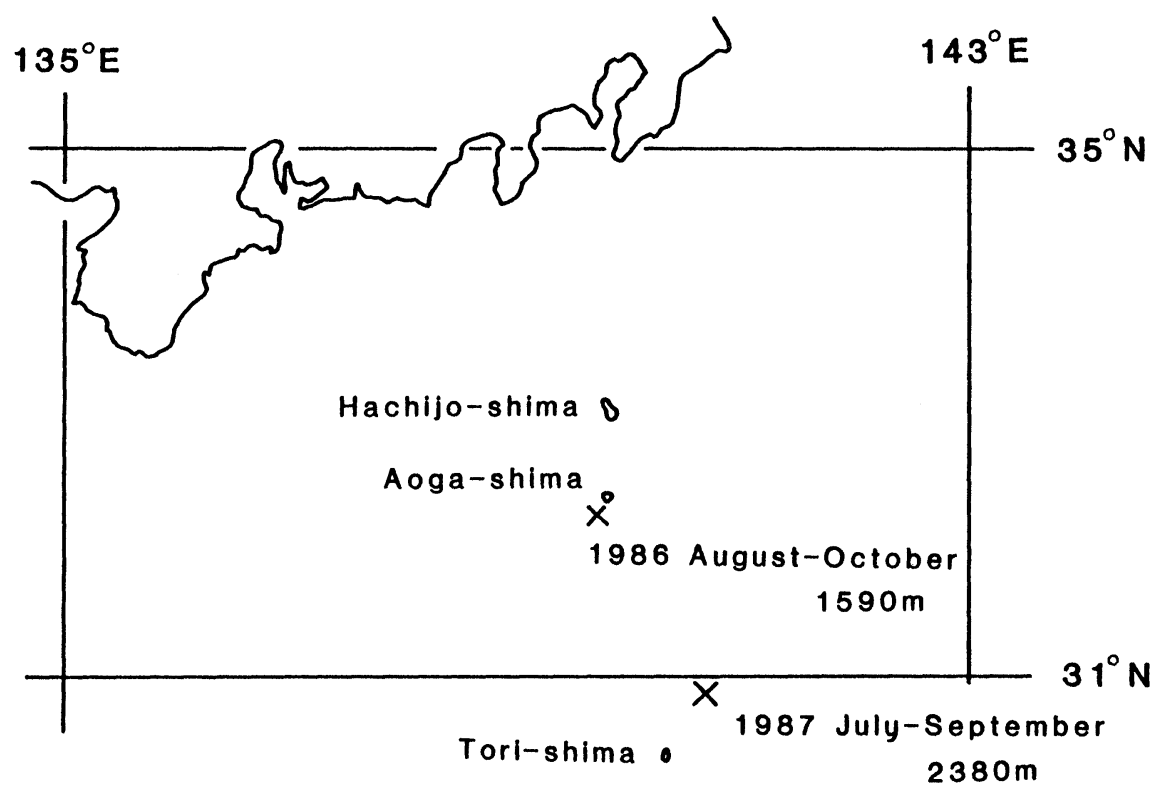

Fig. 6. Map showing the sites of installation of the proton magnetometer and the OBM-C3 fluxgate magnetometer. The sites are marked by $X$.

Table 2. The locations and water depths of the installation sites.

\begin{tabular}{ccccc}
\hline Year & & Lat. & Lon. & Depth \\
\hline 1986 & OBP & $32^{\circ} 14.9^{\prime} \mathrm{N}$ & $139^{\circ} 42.6^{\prime} \mathrm{E}$ & $1590 \mathrm{~m}$ \\
& OBM-C3 & $32^{\circ} 14.3^{\prime} \mathrm{N}$ & $139^{\circ} 40.7^{\prime} \mathrm{E}$ & $1600 \mathrm{~m}$ \\
1987 & OBP & $30^{\circ} 57.1^{\prime} \mathrm{N}$ & $140^{\circ} 39.1^{\prime} \mathrm{E}$ & $2380 \mathrm{~m}$ \\
& OBM-C3 & $30^{\circ} 57.3^{\prime} \mathrm{N}$ & $140^{\circ} 39.3^{\prime} \mathrm{E}$ & $2370 \mathrm{~m}$ \\
\hline
\end{tabular}

It is found from this comparison that a sharp decrease occurred in the readings from the OBM-C3 during the first four days, amounting to $45 \mathrm{nT}$. The difference recovers itself a little during the following five days and then becomes very stable. A gradual change in the difference begins to appear at about 40 days after launch, showing a positive drift of the OBM-C3. The drift rate of the OBM-C3 during the latter phase of the measurement is approximately $+0.27 \mathrm{nT} /$ day. The reason why the drift should have behaved like this is still unknown. One possible reason may be unique discharge characteristics of the lithium battery in the OBM-C3, because the profile shown in Fig. 10 resembles that of the discharge curve of the lithium battery itself. This possibility cannot be straightforwardly accepted, though, if we remember that the battery voltage was stabilized by a voltage regulator. The examination of 

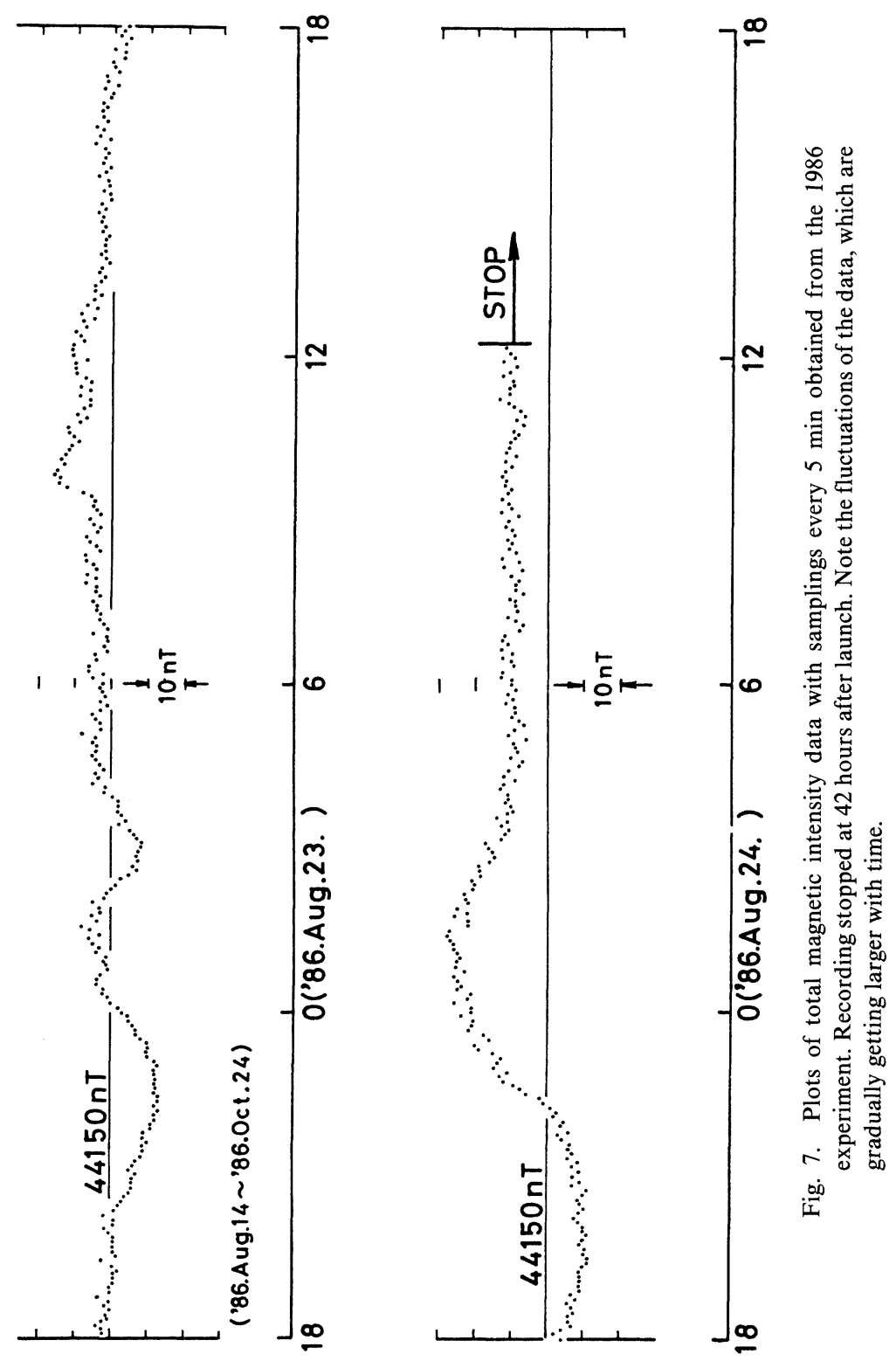


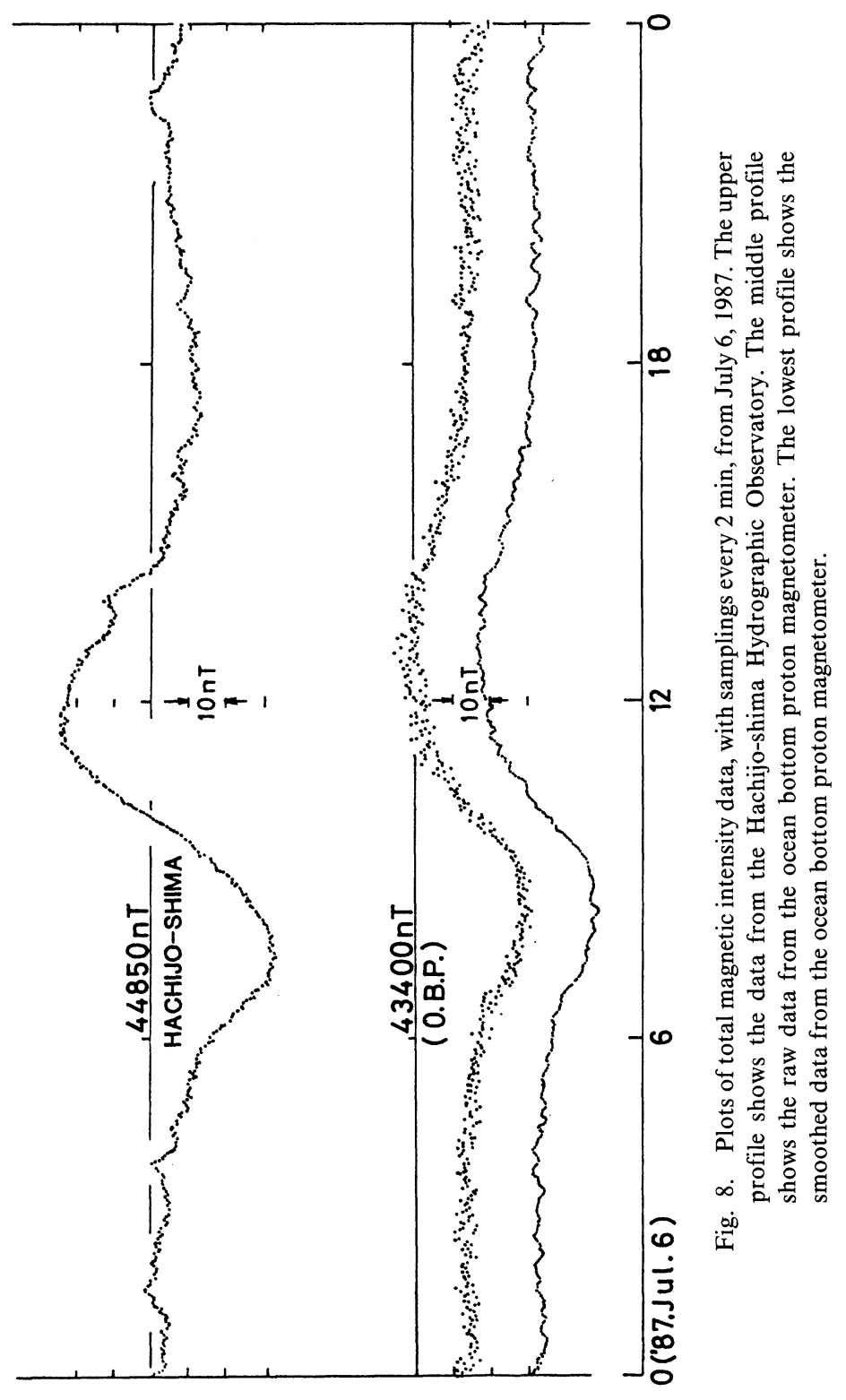




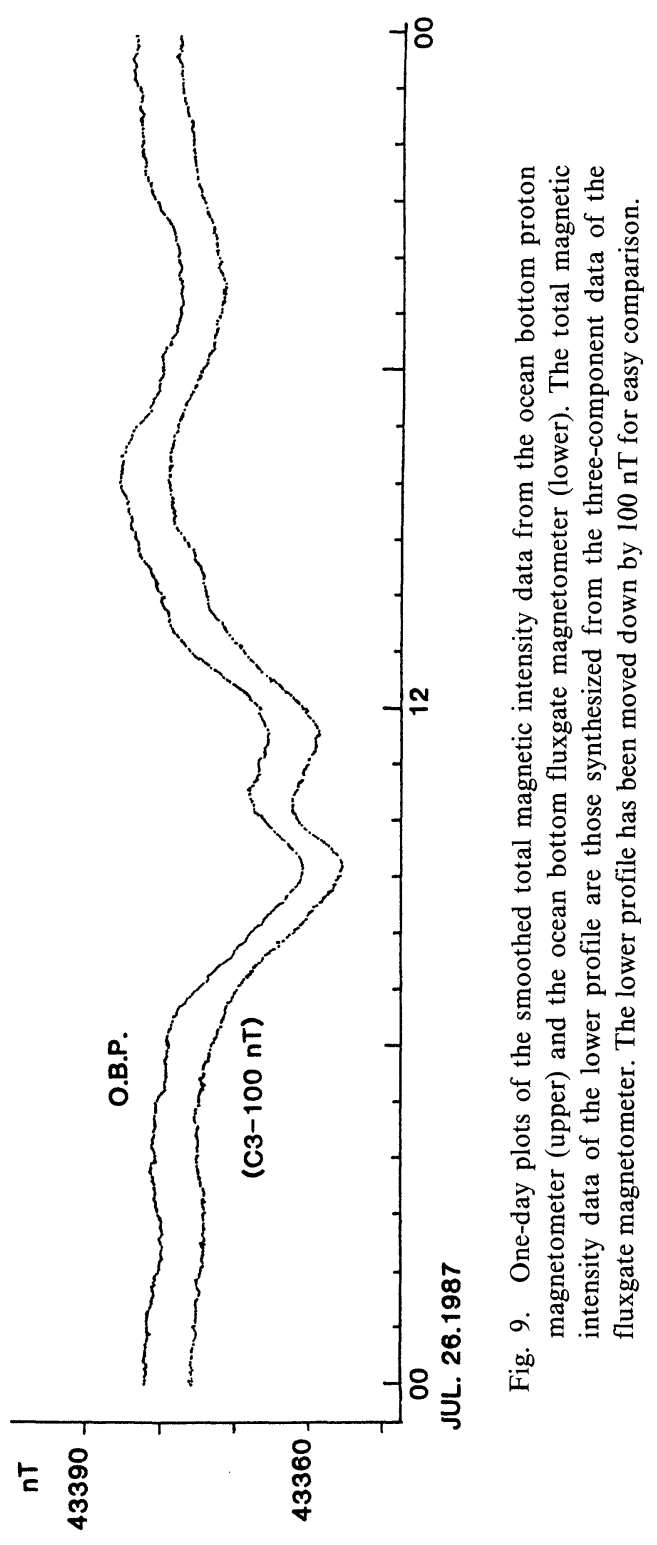




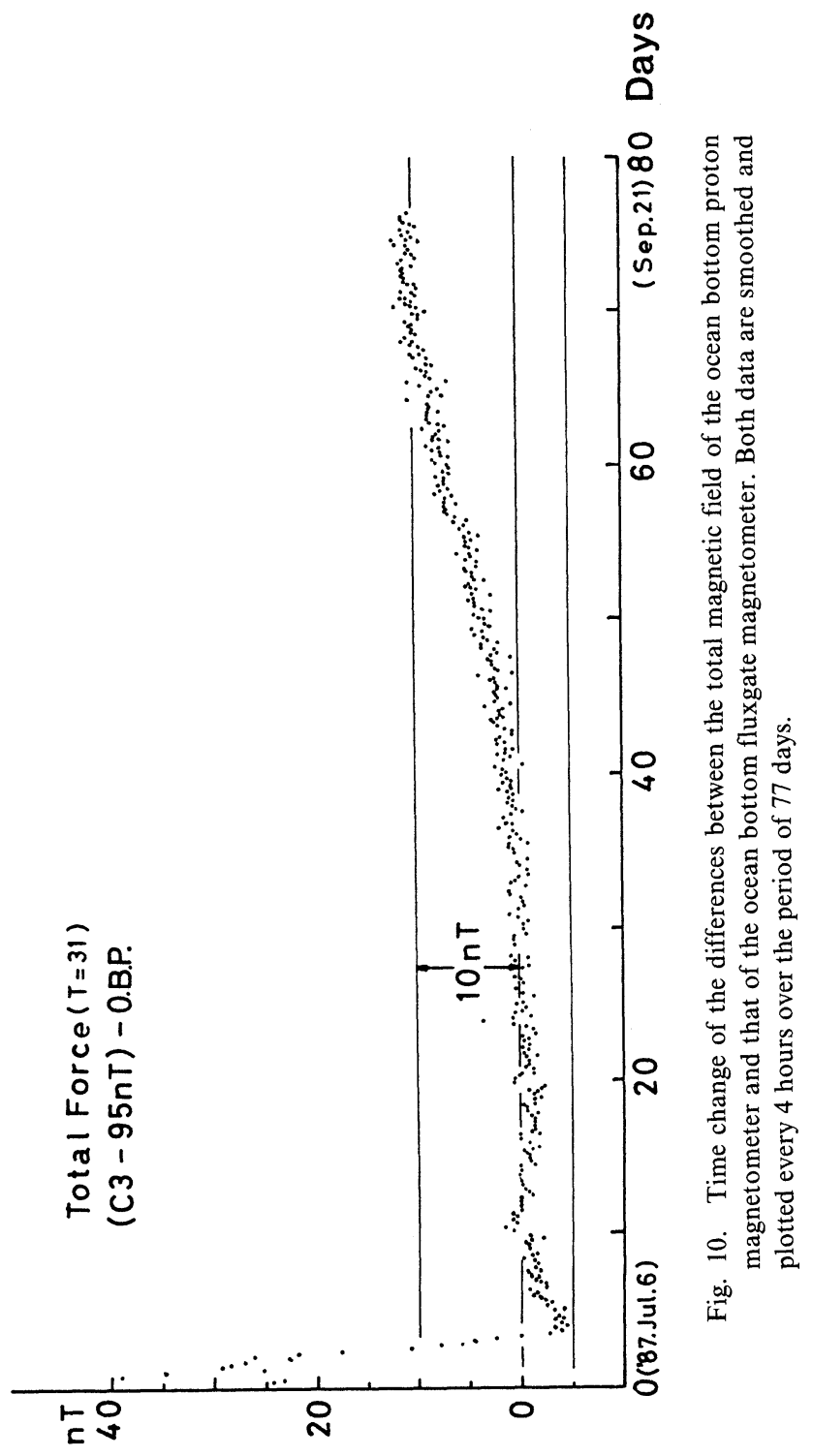


drift characteristics may be conducted in a laboratory on land; however, the magnetic environment on land is generally worse than at the sea floor, particularly when the behaviour of the long-term drift is to be examined. Environmental magnetic disturbances and variations of ambient temperature on land are likely to mask the intrinsic drift of the magnetometer. So, the authors think that this type of strict examination shall be conducted later in a well-equipped laboratory.

Comparison of the measurements using a vector and an absolute scalar magnetometer does not give any indication about the drift of each vector component of the field. The offset of the total magnetic intensity synthesized from the threecomponent values cannot be partitioned into three components. The only information available is the fact that the instability of a vector magnetometer can be evaluated in terms of the deviation of the measurement in the direction of the total magnetic field.

\section{Conclusion}

The three-component magnetic field measured by a fluxgate magnetometer is likely to be associated with a significant drift. In order to evaluate the long-term drift of the ocean bottom fluxgate magnetometer, we have developed a sea floor use proton magnetometer to be used as a reference for comparison. After 2 years of experiments we were finally able to obtain 77-day data on the total magnetic field at the sea floor. Although there were some problems with the proton magnetometer itself, it provided a fairly good set of reference magnetic field data. The results showed that the ocean bottom fluxgate magnetometer OBM-C 3 took an unexpectedly long time ( 4 days) to be stabilized, and that the drift features resembled the discharge curve of the lithium battery used. Although the drift of each component of the vector magnetometer cannot be estimated separately from the total reference field data, it is regarded as a measure to evaluate the reliability of the vector data. The authors believe that this paper has provided a valuable example of conducting a rigorous measurement of the geomagnetic field at a deep ocean floor.

The authors would like to express their sincere thanks to the captain and crew of the Shin-yo Maru of the Tokyo University of Fisheries for cooperating with them in the installation and recovery of the magnetometers, and also to the Third Maritime Safety Headquarters, Maritime Safety Agency and to the Geomagnetic Observatory (Kakioka), Japan Meteorological Agency, for providing them with the magnetic data.

\section{REFERENCES}

Segawa, J., T. Yukutake, Y. Hamano, T. Kasuga, and H. Utada, Sea floor measurement of geomagnetic field using newly developed ocean bottom magnetometers, J. Geomag. Geoelectr., 34, $571-585,1982$.

Segawa, J., Y. Hamano, T. Yukutake, and H. Utada, A new model of ocean bottom magnetometer, $J$. Geomag. Geoelectr., 35, 407-421, 1983. 
Segawa, J., Y. Hamano, T. Yukutake, H. Utada, and H. Toh, A sea floor magnetometer Model OBM-S4-0.1 nT resolution, ROM memory and acoustic release-, J. Geodetic Soc. Japan, 32, 248-273, 1986. 